\title{
The history of the parathyroid surgery
}

\section{A história da cirurgia das paratireoides}

\author{
Marcelo Garcia Toneto1; Shandi Prilli; Leticia Manoel Debon'; Fernando Zucuni Furlan'; Nedio Steffen¹.
}

A B S T R A C T

\begin{abstract}
The authors conducted a review of the major aspects of progression of knowledge about the surgical treatment of hyperparathyroidism. Through literature review, we analyzed articles on the history of the evolution of anatomical, physiological, pathological and surgical knowledge of the parathyroid glands. Because of their unique anatomical features, the parathyroid glands were the last of the endocrine glands to be discovered, which greatly hindered proper treatment until the first decades of the twentieth century. Technological developments in the last 30 years greatly facilitated the location of the glands and hyperparathyroidism surgery. However, an experienced and dedicated surgeon is still essential to the excellence of treatment.
\end{abstract}

Keywords: Parathyroid Hormone. Hyperparathyroidism. Surgery. Parathyroidectomy. History of Medicine.

\section{INTRODUCTION}

Hyperparathyroidism is a condition in which there is an abnormal increase in the levels of parathyroid hormone (PTH), responsible for regulating the level of blood calcium and phosphate. The most common cause of hyperparathyroidism, seen in about $80 \%$ of cases, is the primary gland dysfunction due to an adenoma. Multiple adenomas or hyperplasia of the parathyroid glands are diagnosed in the remaining patients. Rarely the cause of hyperparathyroidism is a result of a parathyroid carcinoma. It is a disease for which therapy may be surgical, which involves the removal of the affected gland. When surgery is indicated in patients without prior treatment, the cure rate approaches 95\% ${ }^{1}$. In cases where the initial operation is not successful, new surgical explorations become necessary, greatly increasing the number of complications and decreasing success rates to about $80 \%{ }^{2}$. Therefore, regardless of the hyperparathyroidism origin, the surgeon who will treat these patients must indisputably have skill, experience and technical knowledge to obtain satisfactory results. Currently, advances in the identification of the glands through preoperatively performed diagnostic tests greatly facilitated parathyroid glands surgery. Frozen section biopsies ${ }^{3}$, intraoperative measurement of PTH levels ${ }^{4}$ and less invasive procedures ${ }^{5}$ allow great improvement in patients' quality of life $e^{6}$. However, the identification of the parathyroid glands, the recognition of their important role and the understanding of diseases that affect them traveled a long journey to the present state of knowledge. Since inception, the history of the parathyroid glands is full of incidental findings, often the case in medical history.

The aim of this study is to provide the reader with a historical review of the discoveries fundamental to the understanding of the parathyroid glands and to discuss the current role and future prospects of surgery for the treatment of hyperparathyroidism.

\section{ANATOMY OF THE PARATHYROIDS}

The parathyroid glands originate from the third and fourth pharyngeal pouches and are usually located next to the thyroid gland. They more commonly lie adjacent to the capsule at the posterior face of the thyroid, two on the upper pole and two on the lower, although sometimes they may be located within the gland. A small number of patients can have three, five or, occasionally, a greater amount of glands. Anatomical variations in location are frequent, and they can be found even in the mediastinum near the thymus ${ }^{7}$. Each gland measures between three and six millimeters, weighing approximately 30 to 40 milligrams. During surgery, they can be diffi-

1 - Faculdade de Medicina da Pontifícia Universidade Católica do Rio Grande do Sul (PUCRS), Porto Alegre, RS, Brasil. 
cult to distinguish from the thyroid and the adjacent fat. However, their mustard-yellow color is quite characteristic. Probably because of these anatomical peculiarities, they remained ignored in the treaties of medicine, being described only in 1850 by the curator of the Museum of Natural History of London, Sir Richard Owen. The discovery came with an autopsy of a rhinoceros. Owen described it as "a small compact yellow glandular body attached to the thyroid at the point where the veins emerged" 8 . The famous German pathologist Rudolph Virchow may have identified one parathyroid gland in 1863, when he described a structure in the cervical region, emphasizing that it was not an accessory thyroid gland or lymph node, or any other structure that was familiar to him, though showing no interest in the finding ${ }^{8}$. Despite these initial descriptions, it was several years until, in 1880, a 25-yearold Swedish medical student, Ivar Sandström, definitively elucidated the existence of the parathyroid glands. In his paper entitled "On a New Gland in Man and Fellow Animals", he described the presence of a gland hitherto unknown in dogs, cats, rabbits and other animals. Then he initiated dissections in about 50 corpses and confirmed the presence of these glands in humans, naming them parathyroids due to their location ${ }^{9}$. In a detailed way, he described coloration, shape, variations in the location of glands and held a detailed microscopic analysis. As his report was a long one, about 50 pages, the editors of the time rejected it, and he managed to publish their findings long after, and only in his mother tongue ${ }^{10}$. The description in a little widespread language, associated with lack of understanding about the function these small glands, caused Sandström not to receive the proper recognition for his findings. Sandström, who received the physician title in 1887 , was so disturbed by the lack of recognition of his discovery that fell into a deep depression. Perhaps this fact may have contributed to his suicide at the age of 37 .

\section{THE DISCOVERY OF THE RELATIONSHIP BETWEEN CALCIUM AND THE PARATHYROID GLANDS}

Hypercalcemia occurs when serum calcium levels are high. It is a frequent diagnosis in clinical practice, which occurs when the calcium entry into the circulation exceeds its excretion in the urine or their deposition in bones. Among the most common etiologies, there is the exacerbated function of the parathyroid glands. Hyperparathyroidism results from increased production of PTH, a hormone that regulates the metabolism of calcium and phosphorus. When the excess in PTH production comes from a parathyroid dysfunction in itself, it is called primary. When it comes in response to low plasma levels of calcium, as in vitamin D deficiency situations or chronic kidney disease, it is called secondary. About $90 \%$ of hemodialysis patients have secondary hyperparathyroidism ${ }^{11}$. Hyperparathyroidism is tertiary when occurring in chronic renal failure patients undergoing kidney transplantation who persist with high levels of PTH. Regardless of its origin, the excess production of parathyroid hormone is harmful to the metabolism and should be treat$\mathrm{ed}^{12}$. The resection of the parathyroid glands plays a key role in the management of such patients, its indications being currently well-defined ${ }^{13}$.

The term tetany describes a set of neuromuscular symptoms caused by nervous system hyperexcitability, which can vary from perioral paresthesias to cramps and muscle stiffness ${ }^{10}$. The contracture of the extremities, with or without peculiar seizures, has been described about 100 years ago when Corvisard introduced the term tetany for the first time in $1852^{14}$. Trousseau, in 1862, and Chvostek, in 1876, have defined the clinical signs that characterize it, without, however, defining its origin. The Trosseau signal is present when, by occluding the brachial artery, there is carpal spasm, manifested as flexion of the wrist and metacarpophalangeal joints, extension of the distal phalanges and proximal interphalangeal joints and adduction of the thumb and fingers. To perform this maneuver a blood pressure measurement cuff is placed around the arm and inflated to a level higher than the systolic blood pressure. The Chvostek sign is the presence of spasms of the facial muscles in response to facial nerve percussion in the zygomatic region ${ }^{15}$. The combination of symptoms of tetany after thyroidectomy was first recognized by Anton Wolfer, in 1879, in a patient undergoing total thyroidectomy by Billroth. His explanation for the seizures was that they stemmed from a "brain hyper- 
emia" ensuing in these patients due to the thyroid removal ${ }^{16}$. This explanation led to the development of the theory of detoxification, which assumed that the tremors and convulsions were caused by toxins not removed from circulation by the thyroid and parathyroid glands ${ }^{10}$. The advances in general anesthesia (1840s), understanding the importance of antisepsis (1860s) and hemostasis (1870s) allowed the beginning of the first successful operations on the thyroid in the following decades. The high mortality rate faced by surgeons of the time (over $40 \%$ ) began to reduce, mainly by the work of two remarkable surgeons in this area: Theodor Kocher and Theodor Billroth. The growing success shown through many surgical patients surviving thyroidectomy began to face the emergence of complications hitherto unprecedented for the time. Patients operated by Kocher presented, as complications, signs today clearly associated with hypothyroidism. Interestingly, the Billroth patients rarely developed such symptoms; however, many patients developed severe tetany with fatal outcome. William Halsted, after watching operations of the great masters, found that the difference was probably in the technique. Kocher was extremely meticulous and precise, operating carefully with strict hemostasis. He removed the entire gland and his patients rarely suffered voice changes or tetany due to preservation of the recurrent laryngeal nerve and parathyroids. Billroth, in contrast, worked quickly, with less rigorous hemostasis. Probably the lack of identification increased the risk of parathyroid removal and the remaining thyroid tissue prevented severe hypothyroidism to occur. For his contributions to thyroid gland physiology, pathology and surgery, Kocher received the Nobel Prize in $1909^{17}$.

In 1891, the French physiologist Eugene Gley, when testing in rats, rabbits and dogs, described that tetany occurred after thyroidectomy only if the glands described by Sandström were also removed. Subsequently he confirmed that removal of the parathyroids alone caused the same effect. Based on these findings, he recommended extreme caution to surgeons to avoid damaging the parathyroid glands in thyroidectomy and was probably the first to define the essential character of these glands, although not clearly identifying their functions ${ }^{9}$. That same year, Friedrich von Recklinghausen, a famous German pathologist, first described a condition characterized by widespread decalcification of the skeleton, associated with the formation of cysts in the bones, which he called fibrocystic bone disease, without identifying the source of dysfunction. When evaluating that patient, he described the increase of a parathyroid gland, but he did not establish a causal relationship between the findings ${ }^{9}$. Max Askanazy, in $1903^{18}$, described a tumor in the parathyroid in autopsies on patients who had died with the condition described by von Recklinghausen, though also failing to establish the relationship between the two findings. In the early twentieth century, it became clear that parathyroid removal or ischemia caused tetany. Nevertheles, the main hypothesis was that the glands were responsible for the removal of unknown human body toxins. The first evidence of the relationship between the parathyroid and calcium metabolism arose in 1907, when Jakob Erdheim, an Austrian pathologist who studied the parathyroid glands in patients with bone disease, noted that many patients with bone diseases such as osteomalacia and osteitis fibrosa had increased parathyroids. Unfortunately, he erroneously believed that the glands increase was a compensatory response caused by bone disease. That same year, Erdheim reported the diagnosis of a patient with two simultaneous tumors, one in the parathyroid gland and the other in the pituitary, an omen of the multiple endocrine neoplasia that would be described more than 50 years later. The determination of serum calcium levels, from 1909, finally allowed the association between this ion and the parathyroid glands. William MacCallum ${ }^{19}$ was the first to describe the improvement of tetany in animals with the instillation of a parathyroid extract. As a complement to these studies, he also pioneered the evidence that post-parathyroidectomy tetany could be corrected with calcium injection. Despite the inconsistency of his results, he was one of the first to suggest that the cause of tetany was related to low levels of serum calcium. These data led William Halsted to initiate the use of calcium and parathyroid 
extract in his patients with tetany ${ }^{20}$. Only in 1923, Adolf Hanson, a student at the University of Minnesota, was able to develop a stable and reproducible parathyroid extract from bovine parathyroid ${ }^{21}$. James Collip, a Canadian biochemist, recognized for collaborating in studies to identify insulin, independently developed studies to improve the parathyroid extract and define the best form of administration. In 1925, he proved that tetany and symptoms of hypocalcemia could be appropriately corrected, and obtained the first patent for PTH extract 22. The review of all those data compiled by Boothby, condensing the knowledge of the time, definitely concluded that the parathyroid function was related to the calcium metabolism ${ }^{23}$.

\section{EARLY SURGERY AND INITIAL MISTAKES}

Interestingly, the history of transplants probably began with the parathyroid gland. Anton von Eiselsberg, a Billroth disciple, held the first parathyroids autotransplantation in 1892. He transplanted thyroid and parathyroid tissue to the pre-peritoneal space of cats and demonstrated the absence of tetany and the formation of new vessels after the procedure. In contrast, several surgeons reported return of tetany when the transplants were removed $^{16}$. Felix Mandl ${ }^{24}$, a surgeon in Vienna, confirmed the misunderstanding of parathyroid physiology in the early twentieth century. When treating patients with cystic bone lesions in radiological imaging, which evolved with hip fracture and elevated urinary calcium, he initially tried to transplant parathyroid tissue taken from corpses to improve the clinical condition. With the failure of this form of treatment, on July 30, 1925, he indicated a pioneer neck exploration under local anesthesia for removal of a parathyroid tumor, with resolution of symptoms. Radiologic studies conducted four months after the operation showed significant improvement in bone density. Six months after surgery, the patient was free of bone pain. Despite the operation success, the symptoms returned six years later. After two years of new reviews, and diagnosed with recurrent hyperparathyroidism, the patient was again operated on, with resection of two more parathyroid glands, considered normal on histolog- ical examination. There was no remission of symptoms and the patient died three years after. The autopsy found no signs of parathyroid tissue. Even with the failure in this case, Mandl was responsible for a number of findings that were useful in the following years: he determined that the disease was not bone primary, but originated in the parathyroid glands; he demonstrated that tumor resection could be successful in controlling hypercalcemia; he found the possibility of recurrence and also suggested the possibility of a family illness ${ }^{16}$. Mandl also had the merit of helping Gold and Eiselsberg during an operation to remove a parathyroid adenoma in a patient with von Recklinghausen's disease two years after his pioneering surgery. The documentation of clinical and biochemistry improvement after the surgery was performed through rigorous monitoring of serum and urinary calcium levels. After that operation, the term hyperparathyroidism was first used in the literature ${ }^{24}$. David Barr and Harold Bulger ${ }^{25}$ attended a case with similar clinical presentation in 1926, and indicated cervical exploration with removal of an adenoma in a 56-year-old patient. In a troubled postoperative period, which required high doses of parathyroid hormone and calcium by mouth to treat tetany, symptoms improved and the patient returned to normal life. They were probably the forerunners to define the clinical presentation of hyperparathyroidism with five clinical features: bone thinning, multiple cystic bone tumors, hypotonia and muscle weakness, abnormal calcium excretion in the urine with calcium calculi formation and high serum calcium levels.

One of the most picturesque cases that contributed to the understanding of the anatomy and function of the parathyroid glands occurred in the famous Massachusetts General Hospital ${ }^{26}$. The patient, the US Navy officer Charles Martell, was hospitalized due to severe decalcification of his bone structure. Tests indicated elevated calcium levels consistent with hyperparathyroidism. His neck was surgically explored six times between 1926 and 1932. Surgeons could not the parathyroid glands in the first surgery. Subsequent explorations identified only one gland, considered normal on histologic examination. The patient himself, intrigued by his clinical conditions, 
conducted an extensive literature review in the library of the Harvard University, focusing on locations of ectopic parathyroid glands. After finding an account of mediastinal location of the parathyroid glands in the December 1931 volume of the Acta Medica Scandinavica journal, he realized the possible similarity with his own illness. He then insisted that surgeons carried out another surgical exploration, this time in his mediastinum through a sternotomy, which was then located a large encapsulated adenoma. About $90 \%$ of the lesion was removed, the remaining tissue being subjected to transplantation, which was not effective. Symptoms of hypocalcemia were serious and six weeks after the operation, the patient presented with a ureteral obstruction due a calculus. Then again, he was operated and died because of a laryngospasm after surgery ${ }^{27}$.

\section{HYPERPARATHYROIDISM AS A DISEASE}

The first decades of the twentieth century witnessed the improvement in the diagnosis and treatment of hypoparathyroidism through MacCallum's, Halsted's, Hanson's and Collip's studies. However, the disease originated from the excessive hormone production was still unknown. Apparently, physicians at the Barnes Hospital in St. Louis were the first to define hyperparathyroidism in an article published in 1929: characteristic bone findings, muscle weakness, kidney stones and high levels of serum calcium ${ }^{25}$. The initial operation of Mandl and few other successful cases showed that surgery could be a good treatment option for cases of hyperparathyroidism. Nonetheless, little was known about the pathophysiology of this condition. The finding that many patients undergoing resection of adenomas did not have their symptoms improved worried the surgeons of the time. Patients with bone disease often had renal calculi. Fuller Albright ${ }^{28}$, a North American physician formed by Harvard, after spending a year in Vienna following the work of Erdheim, began to show great interest on calcium metabolism. He undertook studies in patients with kidney stones without bone disease and, for the first time, he could relate the renal condition with the parathyroid diseases. Albright was the first researcher who managed to understand that the genesis of hyperparathyroidism could stem from different etiologies. In 1934, he was one of the pioneers in the distinction between the different types of hyperparathyroidism ${ }^{28,29}$. Understanding the different hyperparathyroidism etiologies led to a change in the paradigm of operations for treatment of hypercalcemia. In patients diagnosed with symptomatic primary hyperparathyroidism, surgery is the only treatment that offers the possibility of permanent cure. In asymptomatic patients, there is some controversy about the indication of surgical removal. Calcium serum $1 \mathrm{mg} /$ dl over the limit, urinary calcium excretion $>400 \mathrm{mg}$, $30 \%$ reduction in creatinine clearance, osteoporosis, bone densitometry and age lower than 50 years are the accepted criteria to indicate surgery ${ }^{30}$. Secondary hyperparathyroidism is treated clinically. However, severe pain or bone fractures, significant itching and calcifications of non-vascular organs in patients refractory to appropriate clinical treatment prompt surgery for this condition. Patients with tertiary hyperparathyroidism are usually treated with total parathyroidectomy with preservation of a small fraction of one of the glands.

\section{THE IMPORTANCE OF PTH MEASUREMENT}

After the first findings of Hanson and Collip, laboratory tests for PTH detection were very inaccurate, hampering its applicability. It took about 40 years before the discovery of a more effective method for the measurement of PTH and other peptides by Berson and Yalow ${ }^{31}$, causing a revolution in the evaluation of such patients. The improvement in the determination of serum calcium and PTH yielded an improvement in the understanding of metabolic disorders related to this important ion. The number of patients diagnosed with hyperparathyroidism, even asymptomatic, increased considerably ${ }^{32}$, making it possible to uncover the various clinical and metabolic aspects related to diseases of the parathyroid glands. Nevertheless, detection methods were not yet sufficiently accurate, causing confusion in some patients, for whom the differentiation between the distinct causes of hypercalcemia was still inadequate. The search for greater diagnostic accuracy originated 
the development of an analytical test carried out by radioimmunoassay by Rosalyn Yalow. From this improvement, obtaining a definitive diagnosis was more readily determined. Due to the relevance of this discovery, the researcher received the Nobel Prize in $1977^{33}$. This facility for the laboratory diagnosis of hyperparathyroidism led to an exponential increase in operations during the late 1980s. Due to improved diagnosis, patients no longer presented with advanced stages disease, and many were still asymptomatic. The responsibility of surgeons in indicating the proper procedure increased considerably. However, there were further discussions about the histologic diagnosis of lesions. Conflicting data in the diagnosis provided by pathologists showed the diagnostic difficulties between adenomas and gland hyperplasia. Obviously, this confusion opened the possibility of inadequate or too aggressive surgical procedures ${ }^{16}$. To try to resolve the therapeutic questions in the treatment of primary hyperparathyroidism Purnell et al. conducted a great analysis of 143 patients followed for ten years ${ }^{34}$. The main findings of this well-conducted study were: 1) there was a great loss to follow-up, both by patients and physicians; 2) lack of consensus on specific monitoring tests; 3 ) absence of predictive factors for disease activation; and 4) recommendation of surgery by an experienced surgeon (minimum of nine to ten operations per year).

\section{THE TECHNOLOGY ADVANCES FACILITATING PARA- THYROID SURGERY}

The success of the aforementioned isolated cases encouraged surgeons to recommend parathyroidectomy as a routine procedure to treat hypercalcemia, soon appearing the first series of cases operated with good results ${ }^{35}$. There was also the realization that hyperparathyroidism was not only associated with the solitary parathyroid adenoma, but also with multiple adenomas and with glandular hyperplasia, which could affect all glands. Founded on this knowledge, bilateral cervical exploration became the recommended routine procedure. Parathyroid surgeries were often prolonged, tedious and unsuccessful operations. Advances in perioperative man- agement, proper positioning of the patient on the operating table, endotracheal intubation and the proper use of drains contributed to the growing success of surgery ${ }^{36}$. However, the biggest challenge was still the precise location of the parathyroid glands. The search for a method for preoperative localization of patients' glands appeared as a need to avoid fruitless or inaccurately indicated explorations that could worsen patients' quality of life. Arteriography was one of the initial methods tried, but failed to demonstrate benefits ${ }^{37}$. Selective blood collection of cervical veins was superior to arteriography, though with difficult conduction and considerable morbidity. Surgical anecdotes of the time, faced with the difficulties of location of the parathyroid glands, originated the quote: "The only localization that a patient needs who has primary hyperparathyroidism is the localization of an experienced surgeon!"38. The use of nuclear medicine was another important advance, as well as the neck ultrasonography, allowing the neck exploration to be unilateral in selected cases $^{39}$.

A new revolution in the treatment of these patients occurred in 1987, when Samuel Nussbaum described a method for rapid detection of $\mathrm{PTH}^{40}$. In the past, the measurement of PTH levels took about 20 hours and it was common to inform the patient, still recovering from surgery, of the need for a new cervical exploration ${ }^{27}$. Due to the few minutes half-life of the active PTH, its rapid measurement during operation, before and after resection of the lesion, renders a higher degree of certainty to the complete withdrawal of abnormal glands. PTH levels falling more than $50 \%$ virtually assures the removal of all affected glands ${ }^{41}$. The introduction of this new detection method allowed greater procedure safety, more conservative operations, lower hypercalcemia recurrence rate, surgery without the need for hospitalization and a reduction of about $40 \%$ of hospital costs ${ }^{42}$. Devices for intraoperative identification through a mapping by marking the parathyroid glands also contribute to achieving a more efficient surgery ${ }^{43}$. The adaptation of minimally invasive techniques now allows performing surgeries with very short hospital stay, less pain, lower cost and minimal scarring, improving the cosmetic aspect ${ }^{44}$. 


\section{FINAL COMMENTS}

The parathyroid glands were the last of the endocrine glands to be discovered, this perhaps being one of the reasons that justify the difficulties in the evaluation of patients with hyperparathyroidism in the last century. The history of parathyroid surgery prospered in a way particularly similar to the history of surgery. Knowledge developed slowly from incidental findings, case reports, chance contributions from pa- tients and medical students, laboratory research and, just recently, more well-designed scientific studies. Patients with hyperparathyroidism may present with a wide spectrum of symptoms, but often are asymptomatic and diagnosis is obtained in a routine examination. Current well-structured guidelines allow treatment to be well oriented, allowing highly satisfactory success rates. That responsibility lies with the surgeons of today, ensuring a surgical procedure of excellence, in appropriate hospitals.

\title{
R E S U M O
}

\begin{abstract}
Os autores fizeram uma revisão dos principais aspectos históricos da progressão do conhecimento sobre o tratamento cirúrgico do hiperparatireoidismo. Por meio de revisão bibliográfica, foram analisados artigos selecionados sobre a história da evolução do conhecimento anatômico, fisiológico, patológico e cirúrgico das glândulas paratireoides. Devido às suas características anatômicas peculiares, as paratireoides foram as últimas das glândulas endócrinas a serem descobertas, o que dificultou sobremaneira seu tratamento adequado até as primeiras décadas do Século XX. A evolução tecnológica ocorrida nos últimos 30 anos facilitou sobremaneira a localização das glândulas e a cirurgia do hiperparatireoidismo. Contudo, um cirurgião experiente e dedicado ao tratamento dessa enfermidade ainda é fundamental para a excelência do tratamento.
\end{abstract}

Descritores: Hormônio Paratireoideo. Hiperparatireoidismo. Cirurgia. Paratireoidectomia. História da Medicina.

\section{REFERENCES}

1. Udelsman R. Six hundred fifty-six consecutive explorations for primary hyperparathyroidism. Ann Surg. 2002;235(5):665-70; discussion 670-2.

2. Sosa JA, Powe NR, Levine MA, Udelsman R, Zeiger MA. Profile of a clinical practice: Thresholds for surgery and surgical outcomes for patients with primary hyperparathyroidism: a national survey of endocrine surgeons. J Clin Endocrinol Metab. 1998;83(8):2658-65.

3. Westra WH, Pritchett DD, Udelsman R. Intraoperative confirmation of parathyroid tissue during parathyroid exploration: a retrospective evaluation of the frozen section. Am J Surg Pathol. 1998;22(5):538-44.

4. Clark $\mathrm{OH}$. How should patients with primary hyperparathyroidism be treated? J Clin Endocrinol Metab. 2003;88(7):3011-4.

5. Howe JR. Minimally invasive parathyroid surgery. Surg Clin North Am. 2000;80(5):1399-426.

6. Sheldon DG, Lee FT, Neil NJ, Ryan JA Jr. Surgical treatment of hyperparathyroidism improves health-related quality of life. Arch Surg. 2002;137(9):1022-6; discussion 1026-8.

7. Prospero JD, Baptista PPR, Amary MFC, Santos PPC. Paratireoides: estrutura, funções e patologia. Acta ortop bras. 2009;17(2):53-7.

8. Dubose J, Ragsdale T, Morvant J. "Bodies so tiny": the history of parathyroid surgery. Curr Surg. 2005;62(1):91-5.

9. Vermeulen $\mathrm{AH}$. The birth of the endocrine pathology: How Erdheim misunderstood parathyroids. Virchows Arch. 2010;457(3):283-90.

10. Hackett DA, Kauffman GL Jr. Historical perspective of parathyroid disease. Otolaryngol Clin North Am. 2004;37(4):689-700, vii.

11. Memmos DE, Williams GB, Eastwood JB, Gordon EM, Cochrane $C L$, Gower PE, et al. The role of parathyroidectomy in the management of hyperparathyroidism in patients on maintenance haemodialysis and after renal transplantation. Nephron. 1982;30(2):143-8.

12. Fraser WD. Hyperparathyroidism. Lancet. 2009;374(9684):145-58. 
13. Bilezikian JP, Silverberg SJ. Clinical practice. Asymptomatic primary hyperparathyroidism. N Engl J Med. 2004;350(17):1746-51.

14. Kafetzis ID, Diamantopoulos A, Christakis I, Leoutsakos $B$. The history of the parathyroid glands. Hormones. 2011;10(1):80-4.

15. Hoffman E. Clinical evaluation of the Chvostek sign. Am Surg. 1960;26:501-5.

16. Organ $\mathrm{CH}$ Jr. The history of parathyroid surgery, 1850-1996: the Excelsior Surgical Society 1998 Edward D Churchill Lecture. J Am Coll Surg. 2000;191(3):284-99.

17. Nobelprize.org [base de dados na Internet]. The Nobel Prize in Physiology and Medicine 1909 [acessado em 15 out 2015]. Disponível em: http://www.nobelprize.org/nobel_prizes/medicine/laureates/1909/ kocher-article.html.

18. Lew JI, Solorzano CC. Surgical management of primary hyperparathyroidism: state of the art. Surg Clin North Am. 2009;89(5):1205-25.

19. MacCallum WJ. The physiology and the pathology of the parathyroid glands. Bull Johns Hopkins Hosp. 1905;86:625-33.

20. Halsted WS, Evans HM. I. The parathyroid glandules. Their blood supply and their preservation in operations upon the thyroid gland. Ann Surg. 1907;46(4):489-506.

21. Li A. J. B. Collip, Hanson and the isolation of the parathyroid hormone, or endocrines and enterprise. J Hist Med Allied Sci. 1992;47(4):405-38.

22. Collip JP. The extraction of a parathyroid hormone which will prevent or control parathyroid tetany and which regulates the levels of blood calcium. J Biol Chem. 1925;63:395-438.

23. Boothby WM. The parathyroid glands: a review of the literature. Endocrinology. 1921;5:403-40.

24. Niederle BE, Schmidt G, Organ CH, Niederle B. Albert J and his surgeon: a historical reevaluation of the first parathyroidectomy. J Am Coll Surg. 2006;202(1):181-90.

25. Barr DP, Bulger HA, Dixon HH. Hyperparathyroidism. JAMA. 1929;92(12):951-2.
26. Cope O. The story of hyperparathyroidism at the Massachusetts General Hospital. N Engl J Med. 1966;274(21):1174-82.

27. Rogers-Stevane J, Kauffmana GJ Jr. A historical perspective on surgery of the thyroid and parathyroid glands. Otolaryngol Clin North Am. 2008;41(6):1059-67, vii.

28. Albright F, Bloomberg E, Castleman B, Churchill E. Hyperparathyroidism due to diffuse hyperplasia of all parathyroid glands rather than adenoma of oneclinical studies on three such cases. Arch Inter Med. 1934;54(3):315-29.

29. Ahmad R, Hammond JM. Primary, secondary, and tertiary hyperparathyroidism. Otolaryngol Clin North Am. 2004;37(4):701-13, vii-viii.

30. AACE/AAES Task Force on Primary Hyperparathyroidism. The American Association of Clinical Endocrinologists and the American Association of Endocrine Surgeons position statement on the diagnosis and management of primary hyperparathyroidism. Endocr Pract. 2005;11(1):49-54.

31. Berson SA, Yalow RS, Aurbach GD, Potts JT. Immunoassay of bovine and human parathyroid hormone. Proc Natl Acad Sci U S A. 1963;49(5):613-7.

32. Wermers RA, Khosla S, Atkinson EJ, Hodgson SF, O'Fallon WM, Melton LJ 3rd. The rise and fall of primary hyperparathyroidism: a population-based study in Rochester, Minnesota, 1965-1992. Ann Intern Med. 1997;126(6):433-40.

33. Nobelprize.org [base de dados na Internet]. The Nobel Prize in Physiology and Medicine 1977 [acessado em 15 de outubro de 2015]. Disponível em: http:// www.nobelprize.org/nobel_prizes/medicine/laureates/1977/yalow-facts.html.

34. Purnell DC, Smith LH, Scholz DA, Elveback LR, Arnaud CD. Primary hyperparathyroidism: a prospective clinical study. Am J Med. 1971;50(5):670-8.

35. Castleman B, Mallory TB. The pathology of the parathyroid glands in hyperparathyroidism: a study of 25 cases. Am J Pathol. 1935;11(1):1-72.17.

36. Esmeraldo R, Paloyan E, Lawrence AM. Thyroidectomy, parathyroidectomy, and modified neck dissec- 
tion. Surg Clin North Am. 1977;57(6):1365-77.

37. Taylor S. Hyperparathyroidism: retrospect and prospect. Ann R Coll Surg Engl. 1976;58(4):255-65.

38. Brennan MF. Lessons learned... Ann Surg Oncol. 2006;13(10):1322-8.

39. Coakley AJ, Kettle AG, Wells CP, O'Doherty MJ, Collins RE. 99Tcm sestamibi--a new agent for parathyroid imaging. Nucl Med Commun. 1989;10(11):791-4.

40. Nussbaum SR, Zahrachnik RJ, Lavigne JR, Brennan GL, Nozawa-Ung K, Kim LY, et al. Highly sensitive two-site immunoradiometric assay of parathyrin, and its clinical utility in evaluating patients with hypercalcemia. Clin Chem. 1987;33(8):1364-7.

41. Gordon LL, Snyder WH 3rd, Wians F Jr, Nwariaku F, Kim LT. The validity of quick intraoperative parathyroid hormone assay: an evaluation in seventy-two patients based on gross morphologic criteria. Surgery. 1999;126(6):1030-5.
42. Irvin GL 3rd. The William H. Harrige memorial lecture. Parathormone and the disease. Am J Surg. 2007;193(3):301-4.

43. Chen H, Mack E, Starling JR. Radioguided parathyroidectomy is equally effective for both adenomatous and hyperplastic glands. Ann Surg. 2003;238(3):332-7; discussion 337-8.

44. Gagner M. Endoscopic subtotal parathyroidectomy in patients with primary hyperparathyroidism. $\mathrm{Br} \mathrm{J}$ Surg. 1996;83(6):875.

Recebido em: 09/01/2016

Aceito para publicação em: 03/04/2016

Conflito de interesse: nenhum.

Fonte de financiamento: nenhuma.

\section{Endereço para correspondência:}

Marcelo Garcia Toneto

E-mail: mtoneto@terra.com.br 